\title{
Aplikasi Mobile Housekeeping Asisten Rumah Kita (ARUMI) Berbasis Android
}

\author{
Pahmil Khoriji, Indah Dwijayanthi Nirmala \\ Jurusan Teknik Informatika dan Komputer \\ Politeknik Negeri Jakarta, Depok \\ khpahmil@gmail.com, indahdwijayanthi.nirmala@tik.pnj.ac.id
}

Diterima: 17 September 2016. Disetujui: 29 Oktober 2016. Dipublikasikan: Nopember 2016

\begin{abstract}
Abstrak - Kesibukan aktivitas masyarakat di kota-kota besar menjadi dasar tingginya kebutuhan terhadap layanan jasa bersih-bersih rumah. Industri kontraktor jasa kebersihan mengalami kesulitan untuk mempromosikan layanan housekeeping kepada seluruh lapisan masyarakat secara efektif dan efisien dengan biaya yang rendah. Berdasarkan data yang penulis dapatkan dari NetMarketShare, pangsa pasar Android adalah sebesar 53,54 persen dari seluruh pengguna sistem operasi perangkat mobile smartphone. Berdasarkan beberapa kondisi tersebut, maka penelitian ini bertujuan untuk membangun sebuah aplikasi mobile layanan jasa bersih-bersih rumah housekeeping menggunakan sistem operasi Android. Penulis berharap aplikasi ini menjadi solusi bagi masyarakat yang ingin mendapatkan jasa layanan housekeeping dengan mudah dan dengan layanan yang berkualitas.
\end{abstract}

Kata Kunci : android, arumi, aplikasi mobile, housekeeping, smartphone.

\section{PENDAHULUAN}

Jasa housekeeping merupakan layanan jasa untuk mengatur atau menata peralatan, menjaga kebersihan, memperbaiki kerusakan, dan memberi dekorasi dengan tujuan agar rumah, hotel atau properti lainnya tersebut tampak rapi, bersih, menarik dan menyenangkan bagi penghuninya. Kesibukan aktivitas masyarakat di kota-kota besar menjadi alasan tidak memungkinkannnya pekerjaan-pekerjaan tersebut dilakukan sendiri, untuk itu keberadaan aplikasi jasa housekeeping begitu besar peranannya dalam era modern ini untuk membantu pekerjaan tersebut.

Disisi lain, masyarakat relat if kesulitan untuk mendapatkan jasa housekeeping yang profesional dan bisa diandalkan. Berdasarkan hasil wawancara dengan salah satu pelaku industri kontraktor jasa kebersihan bahwa mereka mengalami kesulitan untuk mempromosikan layanan housekeeping kepada seluruh lapisan masyarakat secara efekt if dan efisien dengan biaya yang rendah. Berdasarkan permasalahan yang ada, perlu adanya tentang pembuatan sebuah aplikasi untuk menghubungkan antara masyarakat atau pengguna jasa dan pelaku industri housekeeping. Sehingga, dapat dijadikan solusi yang memudahkan masyarakat atau pengguna untuk memesan dan menggunakan layanan jasa housekeeping dalam menyelesaikan berbagai jenis permasalahan rumah tangga. Maka dari itu, penulis melakukan penelitian tentang "Pembuatan Aplikasi Mobile Housekeeping Asisten Rumah Kita (ARUMI) Berbasis Android Untuk Smartphone".

\section{TEORI PENUNJANG}

\section{A. House Keeping}

Housekeeping adalah bagian departemen yang mengatur atau menata peralatan, menjaga kebersihan, memperbaiki kerusakan, dan memberi dekorasi dengan tujuan agar rumah, hotel atau properti lainnya tersebut tampak rapi, bersih, menarik dan menyenangkan bagi penghuni atau tamu yang menginap[1].

\section{B. Android}

Android adalah sistem operasi untuk telepon seluler yang berbasis Linux. Android menyediakan platform yang bersifat open source bagi para pengembang untuk menciptakan sebuah aplikasi[2].

\section{Android Studio}

Android Studio adalah sebuah IDE yang bisa digunakan untuk pengembangan aplikasi Android, dan dikembangkan oleh Google. Android Studio merupakan pengembangan dari Eclipse IDE, dan dibuat berdasarkan IDE Java populer, yaitu IntelliJ IDEA. Android Studio digunakan untuk perancangan aplikasi dan pembuatan user interface [3].

D. Android Software Development Kit (SDK)

Android SDK adalah tool API (Application Programming Interface) yang diperlukan untuk 
mulai mengembangkan aplikasi pada platform Android menggunakan bahasa pemrograman Java[4]. Android merupakan subset perangkat lunak untuk ponsel yang meliputi sistem operasi, middleware dan aplikasi kunci yang release oleh Google. Saat ini di sediakan Android SDK (Software Development Kit) sebagai alat bantu dan API untuk mulai mengembangkan aplikasi pada platform Android menggunakan bahasa pemograman Java[2].

\section{E. Java}

Java adalah sebuah bahasa pemrograman yang dapat memenuhi kebutuhan organisasi dengan mengimplementasikan aplikasi berbasis internet dan perangkat lunak pada alat, yang terhubung melalui jaringan. Salah satu tujuan dibentuknya bahasa pemrograman Java adalah untuk dapat menulis program yang akan dijalankan pada berbagai macam sistem komputer. Hal ini disebut dengan "write once, run anywhere"[5].

\section{F. $\quad$ PHP}

Menurut[6], PHP (Personal Home Page) adalah pemograman (interpreter) adalah proses penerjemahan baris sumber menjadi kode mesin yang dimengerti komputer secara langsung pada saat baris kode dijalan kan.

\section{G. XAMPP}

Menurut [7], XAMPP adalah sebuah software web server apache yang didalamnya sudah tersedia data base server MySQL dan support php programming. XAMPP merupakan software yang mudah digunakan gratis dan mendukung instalasi di linu $\mathrm{x}$ dan windows.

\section{H. $M y S Q L$}

MySQL adalah sebuah perangkat lunak sistem manajemen basis data SQL atau yang dikenal dengan DBMS( database management system), database ini multithread, multi-user. MySQL adalah Relational Database Management System (RDBMS) yang didistribusikan secara gratis dibawah lisensi GPL (General Public License) [8].

\section{Notepad++}

Menurut[9], Notepad++ merupakan text editor pengembangan dari Notepad bawaan windows yang dirancang untuk mendukung beberapa bahasa pemrograman. Ini merupakan salah satu freeware yang sering digunakan programmer atau developer dalam menyelesaikan skrip kode programnya.

Selain menawarkan plugin-plugin yang dapat di-instal sesuai kebutuhan, tampilan dari Notepad++ juga lebih menarik. Notepad++ juga mendukung berbagai bahasa pemrograman seperti HTML, CSS, dan PHP yang dapat bekerja pada System Operasi Windows.

Kelebihan Notepad++ jika dibanding Notepad bawaan Windows adalah memiliki kelengkapan fitur untuk mempermudah pengguna saat mengedit kode termasuk saat mengedit kode HTML dan kode CSS[10].

\section{J. $\quad U M L$}

Menurut[11], UML atau Unified Modeling Language adalah sebuah bahasa pemodelan untuk sistem atau perangkat lunak yang berpradigma "berorentasi objek". Pemodelan sesungguhnya digunakan untuk penyederhanan permasalahanpermasalahan yang kompleks sedemikian rupa sehingga lebih mudah dipelajari dan dipahami.

\section{K. Use Case Diagram}

Use case diagram merupakan titik awal yang baik dalam memahami dan menganalisis kebutuhan sistem pada saat perancangan. Use case diagram dapat digunakan untuk kebutuhan apa saja yang diperlukan dalam suatu sistem, sehingga sistem dapat digambarkan dengan jelas bagaimana proses dari sistem tersebut, bagaimana cara aktor menggunakan sistem, serta apa saja yang dapat dilakukan pada suatu sistem[12].

\section{Class Diagram}

Menurut[13], Class diagram biasanya digunakan untuk menggambarkan perbedaan yang mendasar antara class-class, hubungan antara class, dan dimana sub-sistem class tersebut.

\section{HASIL DAN PEMBAHASAN}

\section{A. Functional Requirement}

Dari hasil wawancara dengan salah satu pelaku industri serta analis a yang dilakukan terhadap fitur-fitur yang terdapat pada aplikasi dengan layanan sejenis seperti go clean, dan beberapa aplikasi penyedia jasa housekeeping yang lain seperti housejoy, urbanclap ,Bro4u maka requirement yang diharapkan pada aplikasi ARUMI, adalah :

1. User membutuhkan aplikasi yang simple dan mudah digunakan dalam segi user interface maupun prosedur pemesanan pada aplikasi

2. Menyediakan layanan yang paling banyak diminati oleh pengguna rumah tangga adalah : layanan bersih rumah (jasa pembantu), dan laundry.

3. Menyediakan layanan yang diperlukan bagi rumah tangga dan selama ini belum banyak ditawarkan oleh penyedia layanan jasa adalah : jasa tukang, cuci mobil, cuci motor, dan angkat barang. 
4. Harga layanan yang hendak dipesan dapat ditampilkan dengan transparan pada aplikasi sesuai dengan layanan yang dipilih.

5. Data order yang masuk pada aplikasi harus bisa diakses secara online dan tersimpan database.

6. Admin harus dapat mengakses data order dan dapat meneruskan data order kepada asisten team.

7. Menyediakan pilihan menu untuk menampilkan nomor telepon Customer Service ARUMI untuk memudahkan user apabila ada komplain atau ingin bertanya mengenai layanan ARUMI.

8. Hanya dapat mebuat 1 user dengan 1 alamat $e$ mail, hal ini perlu dilakukan agar tidak ada user yang memiliki banyak nama akun pada database yang akhirnya akan terjadi pengulangan / redundance akun yang tidak efektif.

\section{B. Non Functional Requirement}

Berdasarkan wawancara dan analisa yang dilakukan juga dapat disimpulkan beberapa NonFunctional requirement, yaitu :

1. Tidak diperlukan pembayaran menggunakan kartu kredit.

2. Pada aplikasi tidak ada fitur pembayaran. Hal ini karena fitur tersebut kurang efektif terhadap response masyarakat yang lebih terbiasa pembayaran via cash setelah petugas selesai menegerjakan pesanannya.

3. Pemesanan layanan jasa ARUMI hanya dapat diakses menggunakan smartphone berbas is android.

4. Apabila order sudah di konfirmasi dan petugas ARUMI sudah datang kerumah user maka user tidak dapat membatalkan penggunaan layanan.

\section{Desain}

Usecase yang akan dirancang yaitu usecase diagram untuk sistem aplikasi ARUMI. Dengan memiliki 3 aktor yakni dari pihak user, asisten dan admin. Gambar 1 menjelaskan aliran usecase diagram aplikasi ARUMI.

Class diagram yang dijelaskan pada rancangan program in i adalah class diagram sistem yang terpasang pada perangkat android. Gambar 2 adalah rancangan dari class diagram.

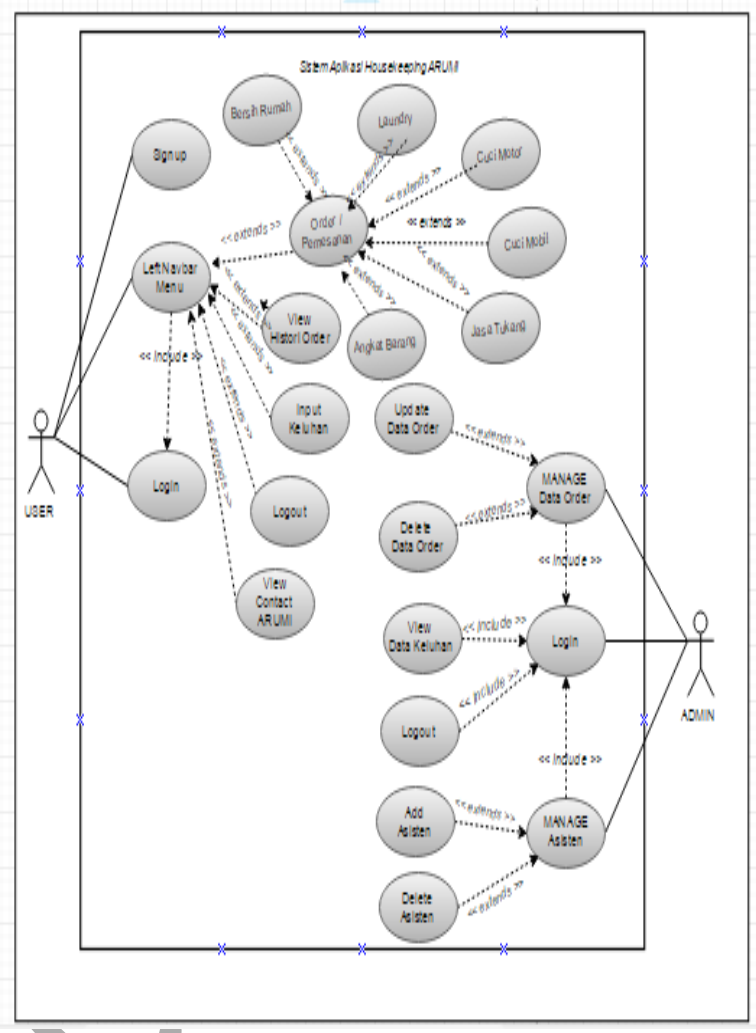

Gambar 1. Use case Diagram Aplikasi ARUMI

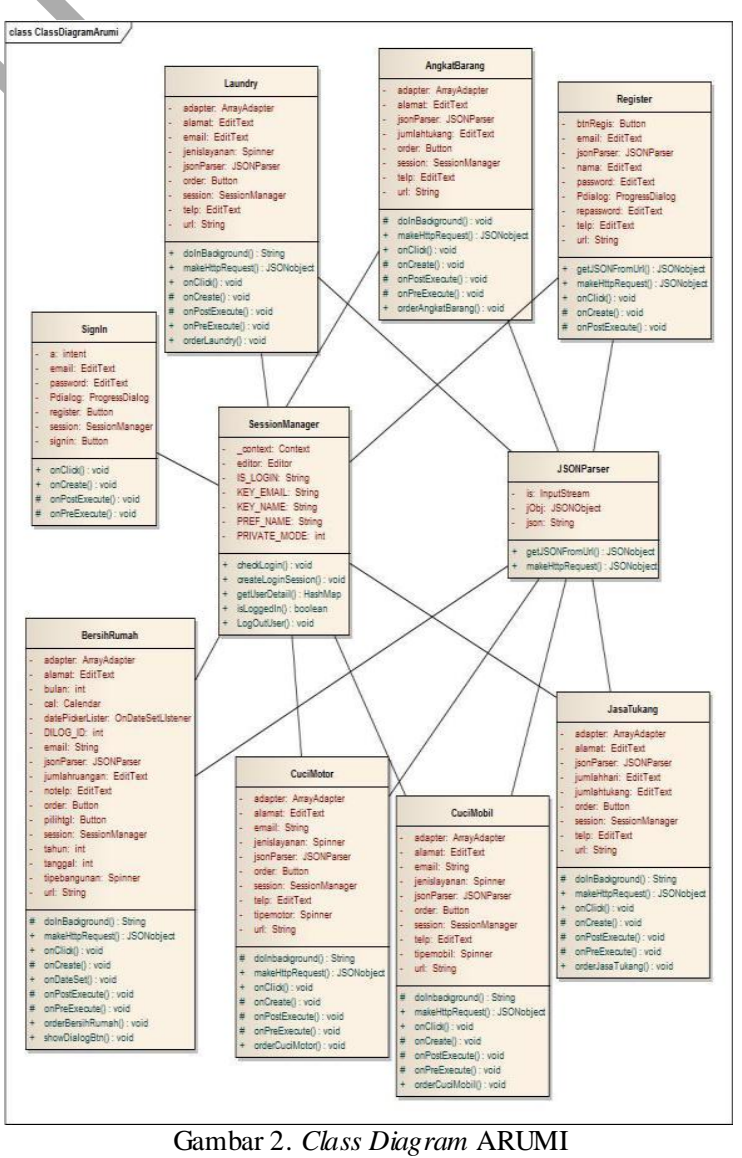


Perancangan data dari aplikasi ARUMI dibuat dengan menggunakan model Entity Relationship Diagram (ERD). ERD tersebut digunakan untuk merancang struktur database pada backend aplikasi ARUMI. Dibawah ini digambarkan perancangan data dari aplikasi A RUMI.

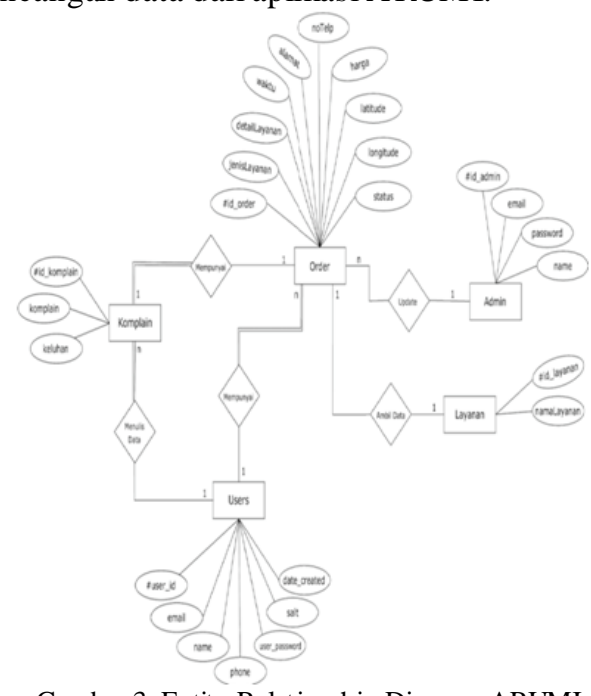

Gambar 3. Entity Relationship Diagram ARUMI

\section{Development}

Berikut merupakan penggalan script yang Penulis buat dalam pembuatan dan pengembangan aplikasi ARUMI dengan bahasa pemrograman android dan PHP.

1. Pembuatan Class GPSTracker

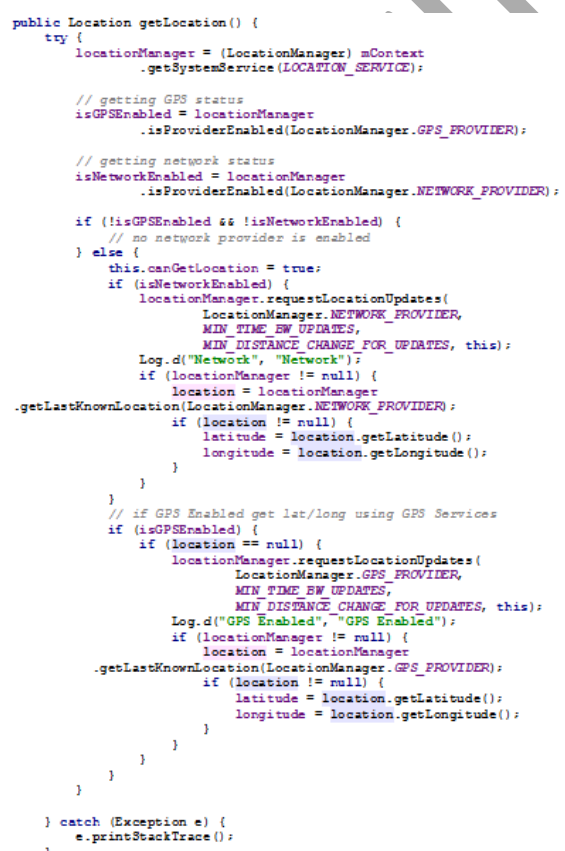

Gambar 4. Script unt uk Mendapatkan Koordinat User
2. Pembuatan Class SessionManager

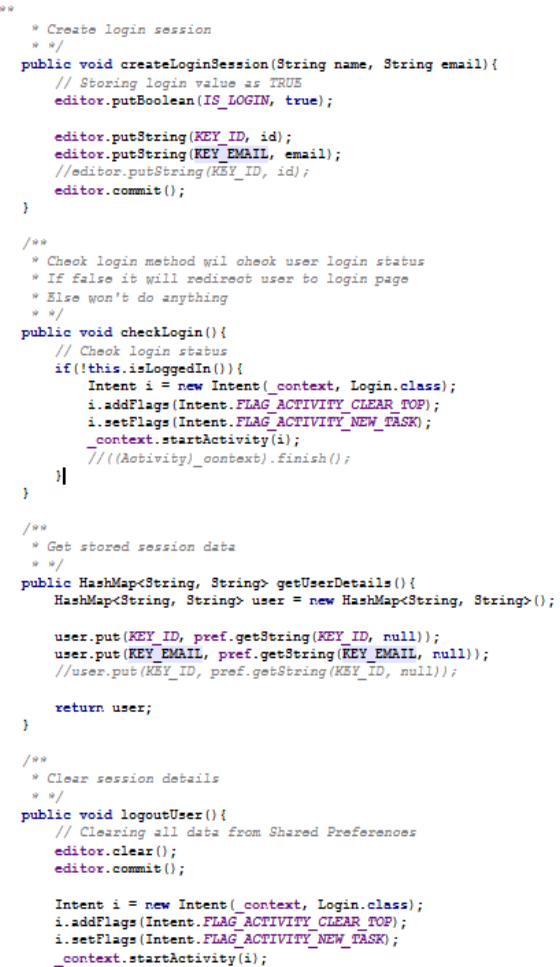

Gambar 5. Script Class SessionManager

3. Pembuatan Class Bersih Rumah (Pemesanan Layanan)

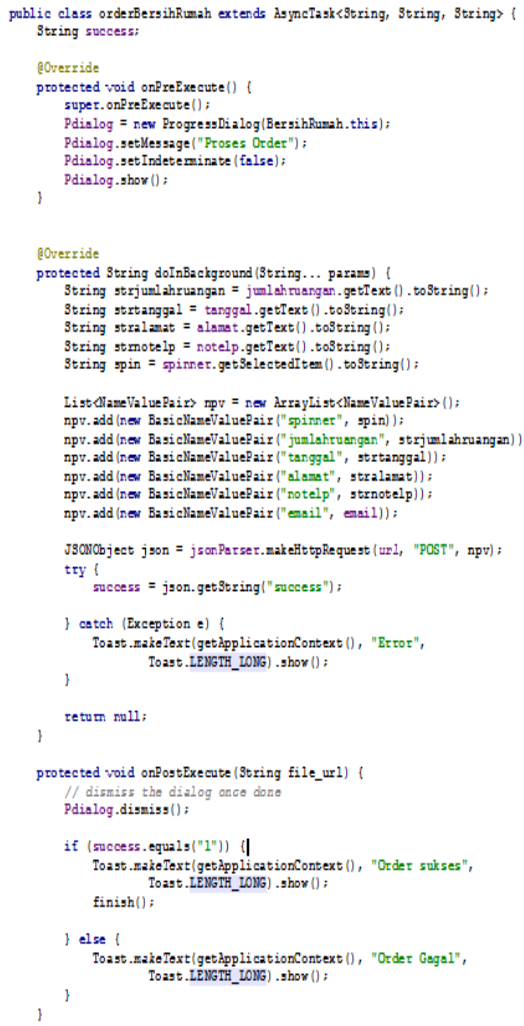

Gambar 6. Script Class Bersih Rumah 


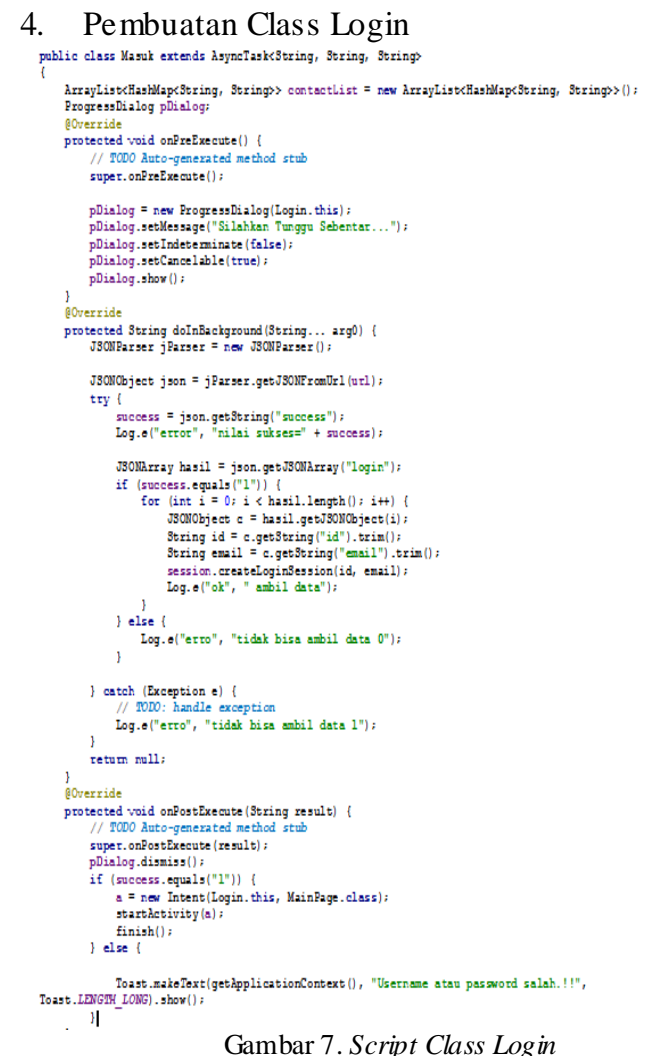

5. Pembuatan Class Register

pablic class daftaraku extends asuncTak<3tring string, suri

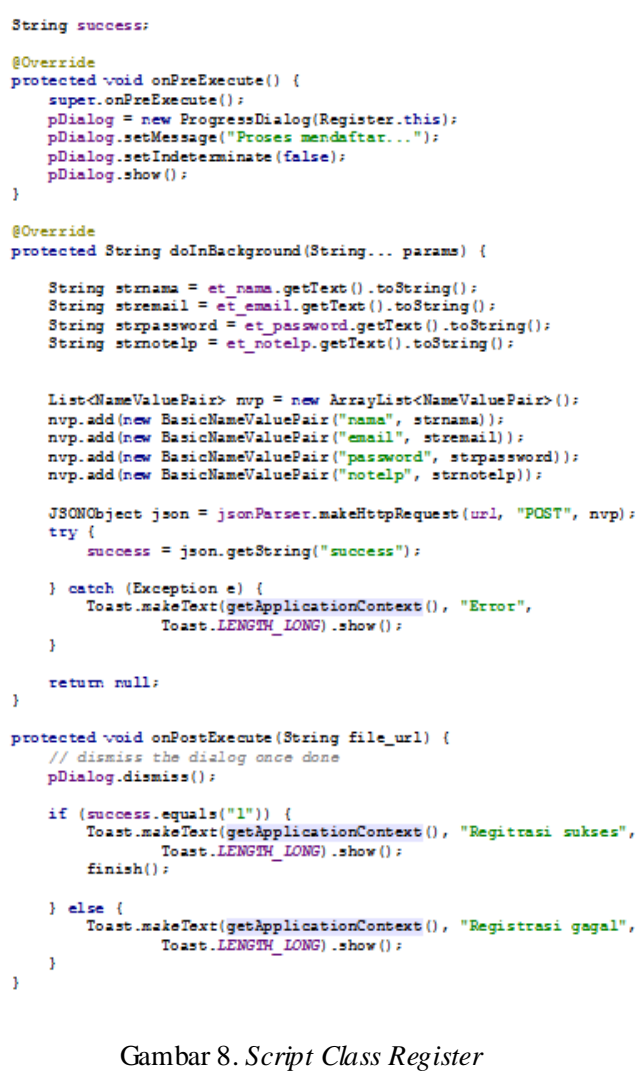

Gambar 8. Script Class Register

\section{E. Deployment}

Proses deployment adalah bagian proses mengintegrasikan aplikasi yang telah dibuat dengan perangkat keras maupun sistem operasi yang akan digunakan untuk menjalan kan aplikasi tersebut[14]. Di bawah ini adalah tabel yang berisi spesifikasi perangkat keras dan perangkat lunak yang dapat menjalan kan aplikasi A RUMI.

TABEL 1. SPESIFIKASI MIN PERANGKAT KERAS DAN LUNAK ARUMI MOBILE

\begin{tabular}{|c|l|l|}
\hline No & \multicolumn{1}{|c|}{ Nama Pe rangkat } & \multicolumn{1}{|c|}{ Spesifikasi Minimum } \\
\hline 1 & $\begin{array}{l}\text { Sistem Operasi } \\
\text { Android }\end{array}$ & $\begin{array}{l}\text { Android 4.0.3 Ice Cream } \\
\text { Sandwich (API 15) }\end{array}$ \\
\hline 2 & RAM & $512 \mathrm{MB}$ \\
\hline 3 & Processor & Dual Core $1 \mathrm{GHz}$ \\
\hline
\end{tabular}

TABEL 2. SPESIFIKASI MIN PERANGKAT KERAS DAN LUNAK BACKEND ARUMI

\begin{tabular}{|c|l|l|}
\hline No & \multicolumn{1}{|c|}{ Nama Perangkat } & \multicolumn{1}{|c|}{ Spesifikasi Minimum } \\
\hline 1 & Sistem Operasi & Windows XP 32 Bit \\
\hline 2 & RAM & $1 \mathrm{~Gb}$ \\
\hline 3 & Processor & Intel Core 2 Duo \\
\hline 4 & Hardisk & $80 \mathrm{~Gb}$ \\
\hline 5 & XAMPP & XAMPP 1.72 \\
\hline
\end{tabular}

F. Implementasi

1. Interface Front End

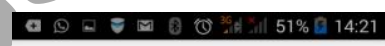

\section{Sign In}

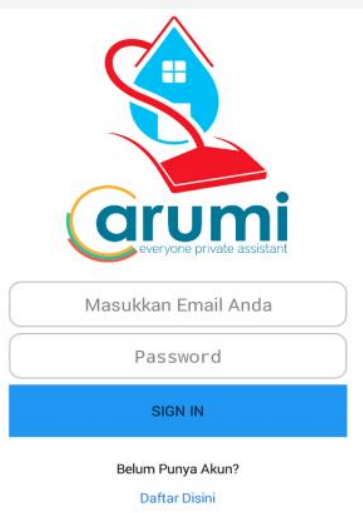

Gambar 9. Halaman Log in 


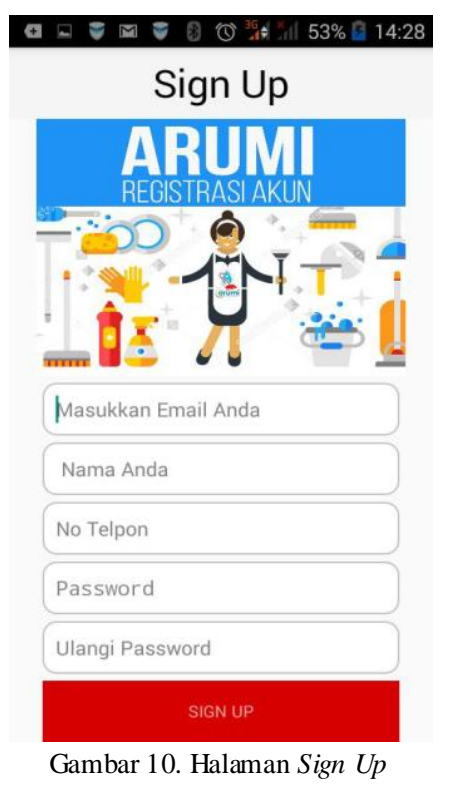

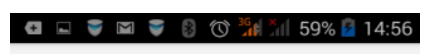

$\equiv$ Layanan ARUMI
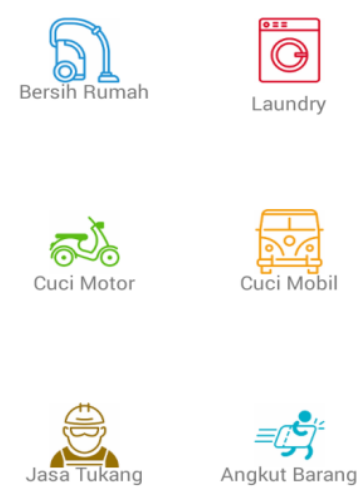

Gambar 11. Halaman Utama ARUMI

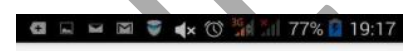

Bersih Rumah

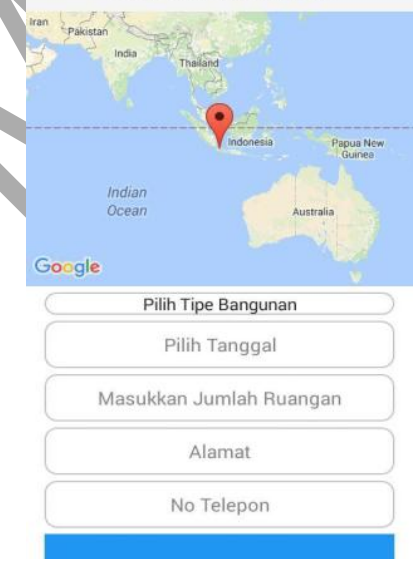

Gambar 12. Halaman Pesan Layanan

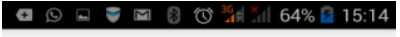

Order Berhasil

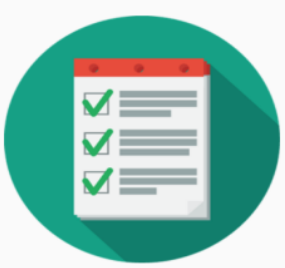

Anda Berhasil

Melakukan Order

Asisten Anda Akan Tiba Dalam Beberapa Menit

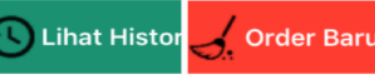

Gambar 13. Halaman Notifikasi Order Berhasil

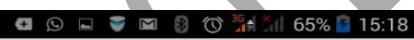

History Order
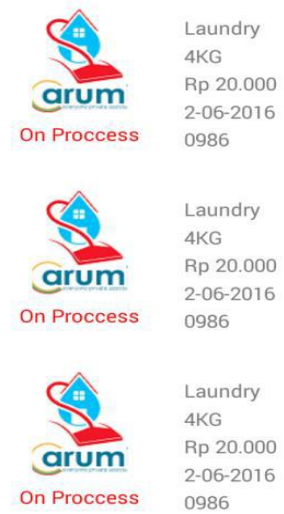

Gambar 14. Halaman History Order

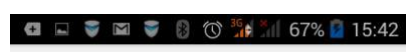

Keluhan
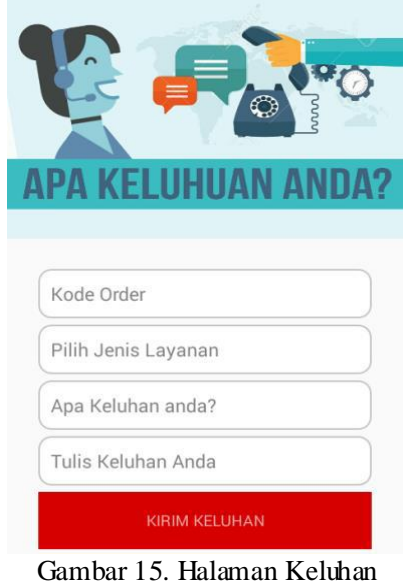

Gambar 15. Halaman Keluhan 


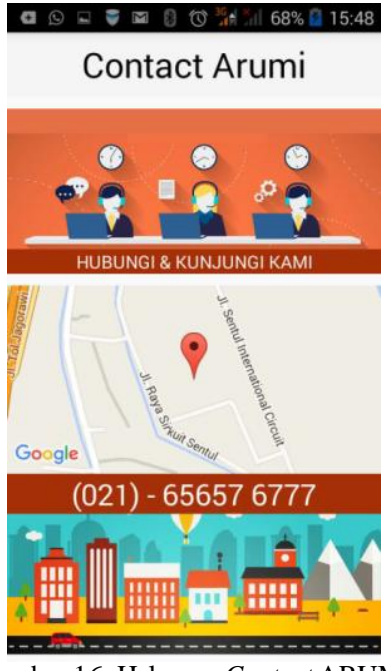

Gambar 16. Halaman Contact ARUMI

\section{Interface Back End}

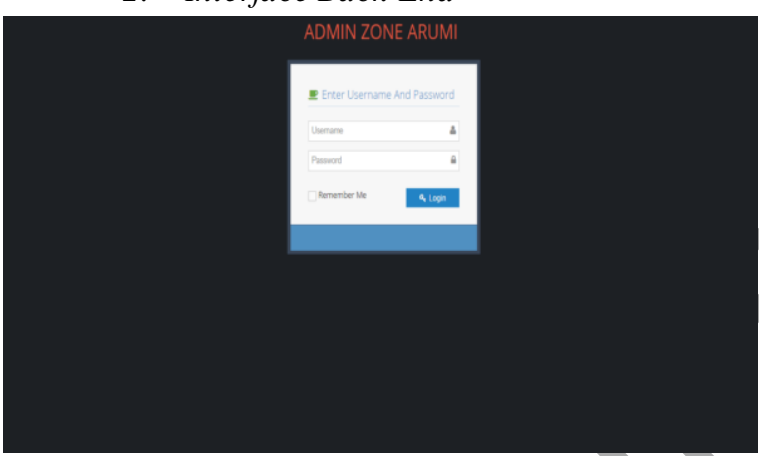

Gambar 17. Halaman Logîn

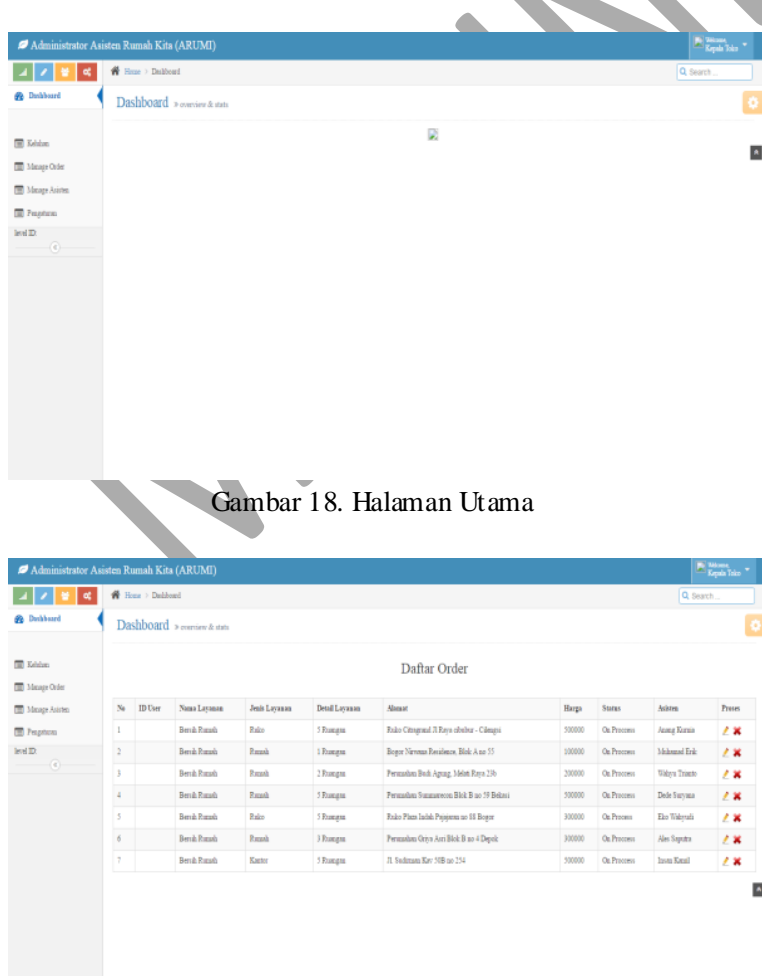

Gambar 19. Halaman Daftar Order

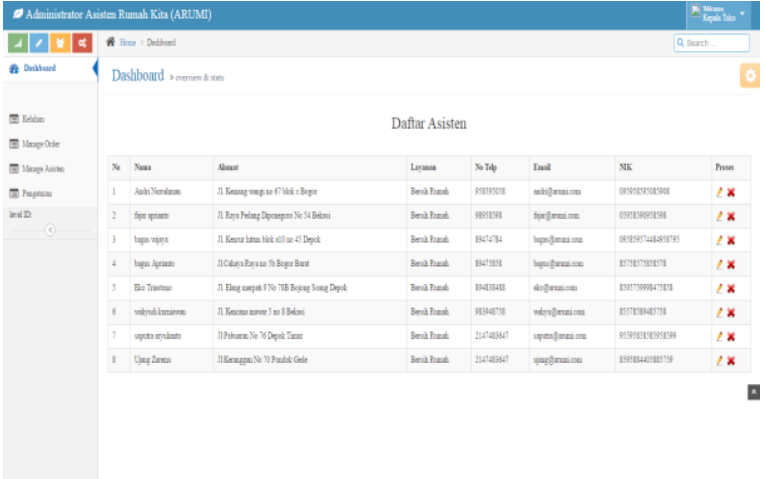

Gambar 20. Halaman Daftar Asisten

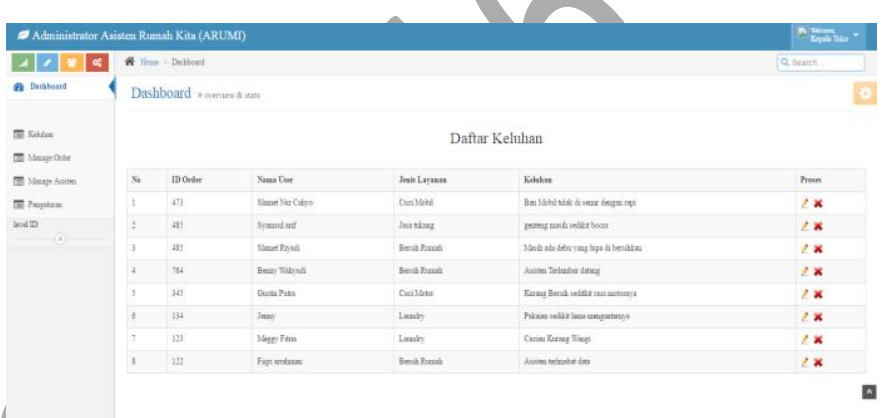

Gambar 21. Halaman Daftar Keluhan

\section{PENGUJIAN}

Pengujian sistem dilakukan dengan metode black box. Pengujian ini dilakukan untuk mengetahui apakah output/hasil sudah sesuai dengan kebutuhan dari user requirement atau belum, kemudian apakah aplikasi sudah sesuai atau belum sesuai dengan requirement, dan pengujian struktur data atau aks es basis data.

Target pengujian aplikasi adalah pengolahan data pada front end ARUMI dengan normal dan dapat terkoneksi dengan basis data pada online server, serta dapat berjalannya fungsi Geo-Location untuk mengambil data lokasi terkini dari pengguna dengan menggunakan GPS pada device yang dipakai pengguna.

TABEL 3. HASIL PENGUJIAN

\begin{tabular}{|c|c|c|c|}
\hline No & Kategori Uji & Hasil & Keterangan \\
\hline 1 & Sign Up User & $\sqrt{ }$ & $\begin{array}{l}\text { Sesuai dengan yang } \\
\text { diharapkan }\end{array}$ \\
\hline 2 & Sign In / Login & $\sqrt{ }$ & $\begin{array}{l}\text { Sesuai dengan yang } \\
\text { diharapkan }\end{array}$ \\
\hline 3 & Input Keluhan & $\sqrt{ }$ & $\begin{array}{l}\text { Sesuai dengan yang } \\
\text { diharapkan }\end{array}$ \\
\hline 4 & Pesan Layanan & $\sqrt{ }$ & $\begin{array}{l}\text { Sesuai dengan yang } \\
\text { diharapkan }\end{array}$ \\
\hline 5 & Pengolahan Data & $\sqrt{ }$ & $\begin{array}{l}\text { Sesuai dengan yang } \\
\text { diharapkan }\end{array}$ \\
\hline 6 & $\begin{array}{ll}\text { Menu } & \text { Contact } \\
\text { ARUMI } & \\
\end{array}$ & $\sqrt{ }$ & $\begin{array}{l}\text { Sesuai dengan yang } \\
\text { diharapkan }\end{array}$ \\
\hline 7 & Menu Log Out & $\sqrt{ }$ & $\begin{array}{l}\text { Sesuai dengan yang } \\
\text { diharapkan }\end{array}$ \\
\hline
\end{tabular}


Setelah dilakukan pengujian terhadap aplikasi ARUMI dapat diketahui bahwa semua fungsi dan fitur aplikasi dapat berjalan dengan baik dan mendapat respon positif dari para pengguna. Dengan adanya aplikasi ARUMI berbasis Android ini dapat memudahkan masyarakat untuk memesanan layanan housekeeping berkualitas yang dikelola oleh perusahaan penyedia jasa housekeeping.

\section{KESIMPULAN}

Aplikasi ARUMI (Asisten Rumah Kita) dibuat dengan beberapa fitur pe mesanan layanan dan jasa sehari-hari seperti jasa bersih rumah, laundry, cuci motor, cuci mobil, jasa tukang dan angkat barang. Dengan adanya fitur tersebut diharapkan dapat mempermudah masyarakat khususnya di perkotaan untuk mendapatkan jasa housekeeping dengan mudah dan dengan kualitas layanan yang baik.

Aplikasi ARUMI dapat memudahkan perusahaan penyedia jasa kebersihan dalam hal promosi jasa yang mereka miliki kepada masyarakat dan dapat menekan biaya promosi yang mereka keluarkan. Aplikasi ARUMI menjadi jembatan penghubung antara user (masyarakat) dengan perusahaan penyedia jasa kebersihan.

\section{REFERENSI}

[1] Nawar, Agus. 2012. Psikologi Pelayanan. Bandung : Alfabeta.

[2] Safaat H, Nazruddin. 2011. "Pemrograman Aplikasi Mobile Smartphone dan Tablet PC Berbasis Android". Bandung : Informatika Bandung.

[3] Finanto, Menda. 2015. "Aplikasi Android untuk Mengatur Switch pada Perangkat Elektronik Nirkabel”. Skripsi. Surakarta: Universit as Muhammadiyah Surakarta.

[4] WoongChul Choi; JungHun Kim, 2011. Development of the REST ful JPIC SDK for the Application Using Public Information. IEEE Ninth International Symposium on Parallel and Distributed Processing with Applications Workshops, Pages: $352-360$.

[5] Deitel, Paul. 2011. Harvey Deitel. Java How to Program Ninth Edition. New Jersey: Prentice Hall.

[6] Sibero, Alexander F.K. 2012. Kit ab Suci Web Programing. Jakarta: Mediakom.

[7] Puspitasari. 2011. Pemrograman Web Database dengan PHP \& MySQL. Jakarta: Skripta.

[8] Peranginangin, Kasiman. (2006). Aplikasi Web dengan PHP dan MySQL. Yogyakarta: Andi.

[9] Mardiani, E., \& Sarniawan. 2014. Aplikasi Penjualan dengan Visual basic, Xampp, dan Data Report. Jakarta: PT. Elex Media Komputindo.

[10] Warangkhana Kimpan; Theerasak Meebunrot; Busaya Sricharoen, 2013. Online code editor on Private cloud computing. International Computer Science and Engineering Conference (ICSEC), Pages: $31-36$.

[11] Nugroho Adi ,ST.,MMSI, 2009, Rekayasa Perangkat Lunak menggunakan UML dan Java, Andi, Yogyakarta

[12] Indrajani, S.Kom, MM. 2011. Perancangan Basis Data Dalam Allin1. Jakarta: Elex Media Komputindo.

[13] Sommerville,Ian.2011.Soft ware Engineering Ninth Edition. Boston: Pearson.

[14] Kustiyaningsih, Yeni. 2011. Pemrograman Basis Data Berbasis Web Menggunakan PHP dan MySQL. Yogyakarta: Graha Ilmu. 